\title{
Anabases
}

ANABASES Traditions et réceptions de l'Antiquité

17 | 2013

Varia

\section{Dioses postmodernos y mitología tecnológica: Ilión y Olympo, de Dan Simmons}

\section{Rosario López Gregoris y Luis Unceta Gómez}

\section{(2) OpenEdition}

\section{Journals}

Edición electrónica

URL: http://journals.openedition.org/anabases/4210

DOI: 10.4000/anabases.4210

ISSN: 2256-9421

Editor

E.R.A.S.M.E.

\section{Edición impresa}

Fecha de publicación: 1 marzo 2013

Paginación: 201-220

ISSN: 1774-4296

\section{Referencia electrónica}

Rosario López Gregoris y Luis Unceta Gómez, « Dioses postmodernos y mitología tecnológica: Ilión y Olympo, de Dan Simmons », Anabases [En línea], 17 | 2013, Puesto en línea el 01 abril 2016, consultado el 14 noviembre 2019. URL : http://journals.openedition.org/anabases/4210 ; DOI : 10.4000/ anabases. 4210 


\section{Dioses postmodernos y mitología tecnológica: \\ Ilión y Olympo, de Dan Simmons ${ }^{1}$ Postmodern Gods and Technological Mythology: \\ Ilium and Olympos by Dan Simmons}

Rosario López Gregoris, Luis Unceta Gómez

\section{Cultura clásica y ciencia ficción}

SOMOS CONSCIENTES AHORA MÁS QUE NUNCA de vivir un momento en el que las manifestaciones culturales no canónicas se han convertido en fuente inagotable de referentes que pueden ser considerados el trasunto contemporáneo de los mitos antiguos. El cine, la televisión, el cómic o formatos más recientes, como la animación o los videojuegos, se han conformado en el caldo de cultivo para fabulaciones modernas, efímeras o perdurables, y con frecuencia deudoras de modelos antiguos. Lo reseñable es que estas expresiones culturales manejan esos referentes de manera desacomplejada y supeditada a sus propios intereses, gracias a la porosidad de la cultura de masas. Paralelamente, la presencia del patrimonio cultural de la Antigüedad en estos formatos modernos, poste-

1 Este trabajo ha sido realizado en el marco del proyecto de investigación «Marginalia. En los márgenes de la tradición clásica» (FFI2011-27645), subvencionado por el MINECO. Ha sido revisado por miembros del proyecto y se ha beneficiado asimismo de las sugerencias realizadas por dos evaluadores de la revista. 
riores al canon tradicional, constituye una prueba innegable de la fortaleza y vitalidad de la cultura grecolatina ${ }^{2}$.

Con esta premisa, el presente trabajo se alinea voluntariamente en una actitud con respecto a la pervivencia del material grecorromano que ha sido interpretada como un "giro democrático" en los estudios sobre la Antigüedad ${ }^{3}$. En ese sentido, constituye un acercamiento que parte de la constatación de que en los fenómenos de recepción de lo clásico se activa un abanico amplio de factores culturales que influyen en la manera en que cada época se acerca a esa herencia, la reelabora y la interpreta. La clave, en última instancia, radica en el traslado del énfasis desde el emisor hasta el receptor ${ }^{4}$, en una forma de análisis que atiende a factores como la percepción y el consumo de la cultura grecorromana por parte de un público no necesariamente versado en ella, la adaptación de las distintas relecturas a las necesidades del momento que las genera o la influencia que ejercen en nuestra percepción de los clásicos algunas manifestaciones culturales contemporáneas, entre otros muchos.

No se trata -no exclusivamente al menos- de un estudio comparativo detallado, que contraponga el arquetipo y su transposición contemporánea, es decir, no interesa tanto la Antigüedad como objeto de estudio en sí misma, cuanto la manera en que esa Antigüedad (o, más precisamente, la idea que cada época genera sobre la cultura grecorromana anti-

2 El cine como receptáculo para la pervivencia de la Antigüedad grecolatina fue pronto legitimado como objeto de análisis académico y cuenta ya con varias décadas de investigaciones a sus espaldas; sin embargo, solo muy recientemente se ha comenzado a abordar con cierta sistematicidad la presencia de lo clásico en otros formatos de la cultura de masas o popular. Sin afán de exhaustividad, cabe mencionar la obra pionera de G. NiSBET, Ancient Greece in film and popular culture, Exeter, ${ }^{2} 2008$ ( $1^{\text {a }}$ ed. 2006), provocación declarada al elitismo tradicional de los estudios clásicos, como señala Joanna Paul en su reseña a la primera edición en BMCR (<http://bmcr.brynmawr.edu/2008/2008-02-31. html> [13-07-2012]). Relevantes son también los trabajos reunidos en D. Lowe \& K. Shahabudin (eds.), Classics for all: Reworking Antiquity in mass culture, Newcastle, 2009, que incluyen un análisis sobre formatos como la radionovela, los videojuegos o el cine pornográfico, o la completa monografía de Cl. AzIzA, Guide de l'Antiquité imaginaire, Paris, Les Belles Lettres. Acerca de las relaciones entre el teatro latino y la sitcom o comedia de situación televisiva, puede verse R. LÓPEZ \& L. UNCETA, "Comedia romana y ficción televisiva: Plauto y la sitcom», Secuencias. Revista de Historia del cine 33, 2001, p. 93-110. También el cómic, otro formato obviado hasta épocas recientes por los círculos académicos, comienza a recibir la atención que merece; pueden verse al respecto los trabajos reunidos en G. Kovacs \& C.W. Marshall (eds.), Classics and comics, New York, 2011 o R. GonzÁlez, "Orfeo y Eurídice en el cómic», Cuadernos de Filología Clásica (Estudios Latinos) 30, 2010, p. 193-216.

3 Cf. L. Hardwick \& Ch. STRay, «Introduction: Making connections», en id. (eds.), A Companion to classical receptions, Oxford, Blackwell, 2008, p. 1-9 (p. 3).

4 F. García JuRAdo, Encuentros complejos entre la literatura latina y las modernas: una propuesta desde el comparatismo, Madrid, 1999, se refiere a este tipo de acercamientos alternativos, que tienen en cuenta las relaciones entre las literaturas antiguas y las posteriores, como «encuentros complejos». 
gua) mantiene su influencia, más poderosa de cuanto pueda creerse, en determinadas manifestaciones culturales y artísticas propiamente contemporáneas 5 .

La presencia de lo clásico en la ciencia ficción no constituye ninguna rareza, aunque en muchas ocasiones su uso resulte anecdótico y meramente estético. El mundo clásico, como paisaje exótico y producto extraño, además de elemento de prestigio, ha tenido y tiene buen encaje en las narraciones fantásticas, porque la fantasía, es decir, el procedimiento para la creación de mundos imaginarios, es perfectamente equiparable a los elementos rectores de los relatos mitológicos de la Antigüedad ${ }^{6}$. Pero con la diferencia de que el mito, más que una cuestión de creencias ${ }^{7}$, era el vehículo para explicar la realidad en el mundo antiguo, mientras que en la literatura fantástica y en la ciencia ficción el mito suele resultar un mero complemento que colabora en la creación del ambiente de irrealidad que este género persigue ${ }^{8}$. De tal modo, ciencia ficción y literatura fantástica no pretenden explicar la realidad, sino inventar un mundo paralelo con sus propias reglas, paisajes y héroes, aunque no se les puede negar una función pedagógica en sus casi obligados planteamientos utópicos ${ }^{9}$, causa más que probable de su éxito. Y sin embargo, salvo algunas excepciones ${ }^{10}$, la pervivencia del elemento

5 En su artículo "Classical receptions in science fiction» (Classical Reception Journal 4, 2012, p. 127-147), B. M. Rogers y B. STEVEns se manifiestan en términos semejantes (véase especialmente p. 134).

6 Véase al respecto R. López Gregoris, «¿Qué es realidad y qué ficción en la literatura y la mitología antiguas?», en A. Cascón et al. (eds.), Donum amicitiae. Estudios en homenaje a Vicente Picón, Madrid, p. 305-317, donde se da cuenta de las semejanzas y diferencias entre relato mitológico y relato fantástico. Aunque diferenciadas por la crítica en la actualidad, la literatura fantástica y la ciencia ficción constituyen territorios colindantes cuyas fronteras no siempre se pueden definir con nitidez.

7 Tanto en Grecia como en Roma, y a diferencia de lo que ocurre en las religiones reveladas, la mitología no era en realidad materia para la creencia; cf. P. VeYNE, Les Grecs ont-ils cru à leurs mythes?, Paris, Le Seuil, 1992. De cualquier modo, para un lector moderno, ambos mundos, el de la mitología y el de la literatura fantástica o la ciencia ficción, son irreales (cf. B. Rogers \& B. SteVens, «Classical receptions...», p. 137).

8 El «extrañamiento cognitivo» al que se refiere D. Suvin en Metamorphoses of science fiction (New Haven, Yale University Press, 1979, passim). De hecho, muchos héroes de cómic están forjados sobre la plantilla de los dioses y los héroes antiguos (cf. L. UNCETA, «Mito clásico y cultura popular: reminiscencias mitológicas en el cómic estadounidense», EPOS 23, 2007, p. 333-344); por ello todos ellos resultan parecidos y familiares.

9 U. Eco, Apocalípticos e integrados, Barcelona, ${ }^{2} 2010$, p. 412.

10 Entre las que pueden mencionarse F. GARCíA JURADO, «Literatura antigua y modernos relatos de terror: la función compleja de las citas grecorromanas», Nova Tellus 26, 2008, p. 169-204; A. GonZÁlez-Rivas, "Frankenstein; or the modern Prometheus: una tragedia griega", Minerva 19, 2006, p. 309-326; F. DE Giovanni, "Ancient relics may work modern miracles. Il mito nel racconto fantastico tardo-vittoriano", en P. Esposito (ed.), Da «classico» a «classico». Paradigmi letterari tra Antico e Moderno, Pisa, 2010, p. 190-195; S.C. FredericKs, «Greek mythology in modern science fiction», en W. Aycock \& Th. Klein (eds.), Classical mythology in twentieth century thought and literature, Lubbock 
clásico en estos géneros literarios ha sido escasamente explorada con rigor académico, debido, con toda probabilidad, a un profundo desinterés por parte de este medio hacia géneros o formatos no consagrados como canónicos. Sin embargo, tal como recuerda A. Keen ${ }^{11}$, en última instancia, no debemos perder nunca de vista la diferencia entre los juicios estéticos, cualitativos, sobre estos nuevos productos y formatos, y su significación y preeminencia cultural.

Por ello, por el afán de superar esa supuesta dicotomía entre literatura de divertimento y alta literatura, en este trabajo se pretende analizar el caso de la reescritura de los poemas homéricos llevada a cabo por Dan Simmons, así como determinar los patrones de subversión que propicia la ciencia ficción. Por subversión entendemos los procesos de transformación del hipotexto y el nuevo significado que adquiere la obra gracias a esos cambios. No es una elección azarosa, sino que viene determinada por el sesgo erudito y filológico que el autor imprime a su obra. Solo unos sólidos conocimientos de la épica homérica y una gran capacidad fabuladora como los que demuestra Dan Simmons permiten que esta obra funcione tanto para el gran público como para el especialista.

\section{El autor y su obra}

Dan Simmons (Illinois, EeuU, 1948) es autor de una extensa obra que abarca distintos géneros (horror, suspense, ficción histórica, fantasía), aunque sea principalmente conocido por su producción de ciencia ficción. Su primer gran éxito a escala internacional se debió a la saga bautizada como Los cantos de Hyperión, narración épica compuesta por cuatro novelas ${ }^{12}$, que dan buena cuenta de los profundos conocimientos literarios de su

(TEX), 1980, p. 89-106; S.A. BROWN, "Plato's stepchildren": SF and the classics», en L. Hardwick \& Ch. Stray (eds.), Classical Receptions... 2008, p. 415-427; L. UnCETA, "Breve historia del género cosmogónico: de la Antigüedad al relato de ficción», Nova Tellus 27, 2009, p. 207-227; R. LÓpez Gregoris, «Julio Verne y Virgilio pasean por el infierno: Viaje al centro de la Tierra y otras reescrituras clásicas", Cuadernos de Filología Clásica (Estudios Latinos) 29, 2009, p. 209-226. A. RodRIGUEZ, «Échos contemporains de la Guerre de Troie: l'Iliade dans la bande dessinée, le cinéma, la science-fiction, la littérature de jeunesse (1956-2007)», Anabases 8, 2008, p. 137-150, dedica algunas páginas a la obra que nos ocupa en su trabajo sobre las adaptaciones de la Guerra de Troya en formatos contemporáneos. Véase asimismo el trabajo de revisión mencionado en nota 4, que incluye referencias bibliográficas adicionales.

11 "The " $T$ " stands for Tiberius: models and methodologies of classical reception in science fiction", <http://tonykeen.blogspot.com.es/2006/04/t-stands-for-tiberius-models-and. html> [18/07/2012], versión ampliada de una comunicación presentada en 2006 en la Classical Association Conference (Newcastle).

12 Hyperion (1989), The fall of Hyperion (1990), Endymion (1996), The rise of Endymion (1997). La primera de la serie fue merecedora de los premios Hugo y Locus a la mejor novela de ciencia ficción. A ella se han dedicado trabajos como Ch. PALMER, "Galactic 
autor, patentes fundamentalmente en la rica intertextualidad con la obra medieval de Geoffrey Chaucer, Los cuentos de Canterbury, y el poema de John Keats, Hyperion.

De un proceder similar se sirve Simmons en la arquitectura de su segunda gran saga, conformada por Ilión (2003) y Olympo $(2005)^{13}$, deudora desde sus títulos de la narración homérica de la guerra de Troya. En este caso, va a combinar esta intertextualidad con ciertos relatos mitológicos griegos, enriqueciéndola o al menos extendiéndola a los sonetos de William Shakespeare y En busca del tiempo perdido de Marcel Proust, concesiones culturalistas que, en realidad, poco aportan a la estructura y desarrollo del argumento de esta imponente construcción intelectual. Junto a ellas, es posible encontrar otras muchas referencias literarias, como La tempestad del mencionado Shakespeare ${ }^{14}$, la poesía de Percy B. Shelley, la de William B. Yeats, Ada o el ardor de Vladimir Nabokov e incluso la Biblia, además de las que mencionaremos más adelante. Y todo ello aderezado con las últimas teorías y especulaciones científicas sobre física cuántica, teoría de cuerdas, agujeros de gusano, viajes en el tiempo y universos paralelos, como impone la preceptiva de un género tradicionalmente situado en los márgenes del canon oficial.

\section{El argumento}

La dilogía combina tres historias paralelas que confluyen en un final apoteósico:

La guerra de Troya, que se desarrolla en un planeta Marte «terraformado» para reproducir un Olimpo habitado por ciertos seres posthumanos que abandonaron la Tierra unos siglos antes y que, gracias al desarrollo de la tecnología cuántica, emulan las personalidades, los poderes y los comportamientos de los dioses griegos ${ }^{15}$. Desde

empires and the contemporary extravaganza: Dan Simmons and Iain M. Banks», Science Fiction Journal 26, 1999, p. 73-90, y L. GENEFORT, Architecture du livre-univers dans la Science Fiction, à travers cinq euvres: Noô de Stephan Wul, Dune de Frank Herbert, La compagnie des glaces de G.-J. Arnaud, Helliconia de Brian Aldiss, et Hypérion de Dan Simmons, Université de Nice-Sophia Antipolis, Tesis doctoral, 1997, <http://tel.archivesouvertes.fr/docs/00/04/58/96/PDF/tel-00004119.pdf> [cons. 18-07-2012].

13 Publicadas en su versión original como dos novelas, la edición italiana dividió en dos partes cada una de ellas, disposición que sigue la versión española a cargo de Ediciones B (Ilión: I. El asedio; II. La rebelión. Olympo: I. La guerra; II. La caída).

14 Clara referencia -en combinación con Caliban upon Setebos de Robert Browning- de algunos personajes fabulosos (Calibán, Ariel y Próspero) que animan el hilo argumental desarrollado en la Tierra, sobre el que no podemos extendernos aquí. En el fondo, está latente en toda la obra (y llega a formularse explícitamente) la idea de que las grandes creaciones de los genios literarios poseen tal fuerza que llegan a plasmarse en mundos alternativos que, eventualmente, pueden coincidir con el nuestro.

15 Esta equiparación entre hombres tecnológicamente desarrollados y divinidades antiguas no es nueva en la ciencia ficción. S.C. FREDERICKS, "Greek mythology...», p. 91-95, proporciona otros ejemplos, entre los que cabe destacarse el caso de la novela de R. Zelazny, 
allí, observan e intervienen del lado de sus respectivos protegidos en el escenario bélico de la guerra de Troya, que reproducen como mero entretenimiento: Héctor y Paris por un lado, asistidos por Afrodita y Apolo, y Aquiles, Ulises y Menelao por otro, ayudados por Hera, Atenea y Hefesto. En esta actividad, los dioses reciben el apoyo de una mano de obra sorprendente: filólogos clásicos que vivieron en los siglos XIX y XX, y han sido resucitados, con sus conocimientos intactos, para comprobar la fidelidad al relato homérico de los acontecimientos que allí están teniendo lugar. Su función de comentaristas queda acertadamente recogida en la denominación con la que se les conoce: escólicos, deformación suficientemente alusiva de la función de los escoliastas antiguos ${ }^{16}$.

En paralelo a este eje narrativo, los moravecs -cuyo nombre es un homenaje al experto en robótica e inteligencia artificial Hans Moravec-, unos organismos biomecánicos que viven en las inclementes lunas de Júpiter, han detectado que una enorme energía cuántica se está desplegando sobre el planeta Marte, por lo que deciden enviar una expedición para averiguar el origen de ese inquietante fenómeno. Tras un inesperado ataque de los dioses, únicamente sobreviven dos de estos seres, esenciales para el desarrollo ulterior de la historia, Mahnmut y Orphu de Ío, el uno, un apasionado de los sonetos de Shakespeare, y el otro, un experto en Proust.

Mientras en Marte entran en contacto culturas tan alejadas y contrarias, en la antigua Tierra sobreviven como dulces criaturas los seres humanos, llamados eloi ${ }^{17}$ en homenaje a La máquina del tiempo de Herbert G. Wells, quienes, ignorantes de su pasado y de su potencial, se dedican a banquetear en una fiesta sin fin, servidos por unos seres robóticos, los voynix ${ }^{18}$, cuyo origen ignoran ${ }^{19}$. No saben leer y han olvidado

El señor de la luz (Lord of light, 1967), con la que la obra de Simmons comparte varios elementos.

16 Los dos poemas de Homero han sido, sin lugar a duda, las dos obras de la Antigüedad que más comentarios, escolios, exégesis y explicaciones filológicas han recibido en la historia del libro en Occidente. Nada es comparable a la tarea filológica que los sabios de la Biblioteca de Alejandría dedicaron a estos dos poemas y, en este sentido, la presencia de los escólicos no hace sino continuar esa tradición.

17 Los eloi son una raza imaginada por H.G. Wells, despreocupada y débil, que vive en un mundo de lujuria; dependen de los morlocks para alimentarse y mantener su mundo idílico. Por su parte, los morlocks son la otra raza de la Tierra, vive sumergida en las profundidades y se ocupa de que todo funcione.

18 Personajes tan misteriosos como el manuscrito Voynich en el que posiblemente se base su nombre. Se trata de un libro de contenido desconocido, escrito en una lengua no descifrada. Al parecer fue publicado en el siglo XV, pero aún está por dilucidar si es un libro científico cifrado o un fraude. En él hay una sección que está recogida en la novela de Dan Simmons: en la parte denominada "biológica» hay varias ilustraciones de mujeres desnudas tomando baños, conectados entre sí por una red de tuberías o cables que recuerdan al protocolo médico que se aplica cuando un humano cae herido.

19 La conexión entre este plano y la guerra de Troya en Marte se establece a través de los paños turín: ingenio tecnológico que permite a quien se lo aplica sobre el rostro asistir 
todos los oficios, mueren y son resucitados por extraños aparatos, hasta que llegan a la cifra fatídica, la décima decena, tras la cual se supone que viven eternamente en los anillos que los posthumanos han construido en torno a la Tierra. Un grupo de elegidos de este rebaño descerebrado, Ada, Daeman, Harman y Hannah ${ }^{20}$, va a vivir una aventura reveladora e iniciática, que va a cambiar el destino de la humanidad.

Estas tres historias avanzan en paralelo hasta que confluyen es una sola con un final redentor: la destrucción del planeta Marte -y consecuentemente de todos los falsos dioses que lo controlaban- y el traslado de todos los habitantes de la Grecia homérica reproducida en Marte al planeta Tierra, que, entretanto, ha debido afrontar su propia guerra contra unos invasores extraños. Y todo ello gracias a la intervención de los moravecs y su tecnología avanzada, que, conscientes de los peligros que acechan a los humanos que aún sobreviven en la Tierra, han intervenido para salvarlos y propiciar una nueva cultura humana.

Por supuesto, hay más elementos narrativos en esta vasta historia, que tiene trazas épicas, no ya por los incontables momentos cruciales, sino por el aliento redentor que anima a los héroes de cada historia.

\section{La subversión}

La radical subversión que Simmons realiza sobre el modelo homérico -evidente en los aspectos que detallaremos a continuación- neutraliza cualquier interpretación de la fuente elegida con una finalidad legitimadora del género que practica. De hecho, de las múltiples escrituras de la Ilíada que se han prodigado últimamente, son precisamente las que se realizan en clave de ciencia ficción las que posibilitan el mantenimiento del aparato divino de la épica antigua, ausente, por ejemplo, en obras como Homero, Ilíada de Alessandro Baricco (2007), Troya, film de Wolfgang Petersen (2004), o la serie de cómics Edad de Bronce (Age of Bronce), que Eric Shanower lleva publicando desde 1998, con lo que se produce la paradoja de que es precisamente este género el que permite una mayor fidelidad al modelo ${ }^{21}$, tal y como se aprecia también en los cómic

como espectador al enfrentamiento, en una suerte de entretenimiento hiperrealista, que, según se informa, genera adicción, como las telenovelas. Este invento quizá remita al test de Turing, que Alan Turing ideó para medir la inteligencia de una máquina.

20 Obsérvese que algunos de estos nombres poseen claras resonancias hebraicas. El carácter mesiánico, que, con respecto a este grupo, desarrolla la última judía viva, Savi (quien asume las funciones de líder y guía espiritual de estos personajes), refuerza esta asociación. Además de los referentes clásicos, el elemento judeocristiano está claramente presente en este marco argumental, que incluye la toma de Jerusalén por parte de los voynix.

21 En cualquier caso, como señala A. KeEN, "The "T" stands for Tiberius...", una diferencia entre el género fantástico y la ciencia ficción es que, mientras que en el primero la presencia divina no se cuestiona y se asume de manera natural, la segunda debe justificarla, habitualmente por medio de una tecnología avanzada, como es el caso. 
de ciencia ficción, firmados por Valerie Mangin, que conforman la serie Chroniques de l'Antiquité Galactique, o, desde presupuestos ligeramente diferentes, Greek Street, de Peter Milligan ${ }^{22}$.

\section{La ficción transgresora}

Partiendo del hecho de que estas obras constituyen un exponente perfecto de los cánones que impone la ciencia ficción, el propio tratamiento de la tradición clásica en el marco de un género al que tradicionalmente se le ha vedado recuperarla constituye ya una primera y fundamental transgresión de los cauces de recepción habituales y considerados legítimos. Y ello, de entrada, permite un uso desinhibido de las fuentes que, en otras manifestaciones, sería considerado un atentado contra el carácter inamovible y monumental de ciertas creaciones ${ }^{23}$. Ahora bien, este tratamiento se realiza desde una aproximación seria, rigurosa y conocedora de la tradición literaria de la Antigüedad.

Así pues, el dilatado bagaje literario de Simmons (que se observa en la profusión de citas textuales de la obra homérica, entre otras, y que, según veremos, le permite incluso ciertas veleidades filológicas) hace de su reescritura del relato clásico un acto subversivo consciente y voluntario, que lo aleja de la consideración de errores por desconocimiento de los que en ocasiones adolecen las producciones dirigidas a un consumo masivo.

Las dos claves que explican la obra, es decir, su hipotexto y su intención subversiva con respecto a su fuente, quedan patentes desde las primeras líneas del primer tomo, pronunciadas en boca del poeta, en este caso un escólico rebelde, Hockenberry, narrador de la historia:

Canta, oh, Musa, la cólera de Aquiles, hijo de Peleo, asesino, ejecutor de hombres destinados a morir, canta la cólera que costó a los aqueos tantos buenos hombres y envió tantas almas vitales y valerosas a la temible Casa de la Muerte. [...] Canta mi cólera, sí, mi

22 Véase al respecto L. UnCETA, "Greek Street. El mito griego visita los bajos fondos», Minerva. Revista de Filología Clásica 25, 2012, p. 189-209.

23 Con todo, no podemos perder de vista el hecho de que la épica debió de ser en la antigua Grecia un género eminentemente popular, a pesar de servir como transmisor de unos valores marcadamente aristocráticos, cuyo consumo, como ha demostrado F. DUPONT, Homère et Dallas. Introduction à une critique anthropologique, Paris, Hachette, 1991, es más comparable a la fruición de una telenovela que a la lectura grave e introspectiva que hacemos hoy en día de un monumento literario fruto de una puesta por escrito que necesariamente soslaya la viveza y mutabilidad de sus orígenes. Así lo apunta, según nos sugiere uno de los evaluadores de este artículo, una crítica de la revista de cine Télérama $\left(\mathrm{n}^{\circ} 3246\right.$, 31 marzo-6 abril 2012) sobre la película Ulisse (M. Camerini, 1954, con K. Douglas y A. Quinn): «Homère, en bon scénariste, avait pensé à tout: des scènes de bataille, de beuveries, d'amour, des femmes nues à queue de poisson, des monstres cruels et des dieux perfides...» (p. 112). 
cólera, oh, Musa, por pequeña e insignificante que pueda ser esa cólera en comparación con la furia de los dioses inmortales, o con la ira del aniquilador de dioses, Aquiles.

Pensándolo bien, oh, Musa, no cantes nada de mí. Te conozco. Te he servido, oh, Musa, incomparable zorra. Y no me fío de ti, oh, Musa. Ni pizca (Ilión I, p. 19-20).

Evidentemente el contraste, buscado, no puede ser mayor: las primeras líneas son una transposición del poema homérico (Il. I, 1-3), con la retórica propia del género y del momento, en la que la alusión a la Musa, como diosa inspiradora y protectora del poeta, constituye un tópico. De pronto y rompiendo la escenografía anterior, aparece la primera persona del poeta, inconcebible en la épica antigua, y comienza la degradación en el tono retórico, para finalmente ordenar a la Musa que no cante su cólera, insulto incluido, «incomparable zorra»-por lo demás, muy épico-, y la expresión de la desconfianza, aún en tono épico, pero con un corolario más bien vulgar, «ni pizca». Toda una provocación para cualquier lector culto.

Esta mezcla de retórica épica y lenguaje coloquial está presente continuamente en la obra, y llama la atención que sea Hockenberry el locutor de este estilo más bien popular -clara estratagema para oír la voz del autor, coetánea del lector-, pues ni los dioses posthumanos lo usan, ni los moravecs son capaces, ni los antiguos humanos hablan en esos términos, adocenados en un lenguaje políticamente correcto, en sintonía con la pusilanimidad que los caracteriza.

Todo ello constituye una muestra patente del sesgo filológico que Simmons imprime a su obra. En su condición de experto conocedor de los poemas homéricos, Hockenberry deja a Simmons la puerta siempre abierta a la incorporación de juegos metatextuales entre la épica antigua y su propia creación ${ }^{24}$, como el que ofrece cuando, transformado en Fénix, el escólico puede asistir a la embajada ante Aquiles, es decir, el conocido problema filológico del dual en el texto de Homero ${ }^{25}$ :

Un montón de estudiosos, antes y durante mi época en la Tierra, argumentaron que Fénix fue un torpe añadido al relato, un personaje incorporado siglos más tarde, lo cual explica la forma dual, pero esta teoría ignora el hecho de que Fénix expondrá el más largo y más complejo argumento de los tres embajadores. Su discurso es tan maravillosamente retórico y complicado que apesta a Homero.

Es como si el poeta ciego se hubiera confundido respecto a si había dos o tres emisarios ante Aquiles y sobre cuál era, exactamente, el papel de Fénix en la conversación que decidiría los destinos de todos (Ilión II, p. 21).

24 Cf. S.A. Brown, “Plato’s stepchildren”...», p. 425.

25 Algunos de los verbos de la embajada ante Aquiles relatada en el canto IX de la Ilíada aparecen en este número, lo que ha planteado la posibilidad de que el texto que nos ha llegado combine dos versiones, una en la que asistiera Fénix y otra en la que no apareciera. Cf. al respecto, P. Carlier, Homero, Madrid, Akal, 2005, p. 89. 
Y de este modo, Simmons juega con la posibilidad de que la obra de Homero hubiera sido influida por los acontecimientos ocurridos en Marte.

Por lo demás, cuando el escólico traiciona a la Musa, se dedica a intervenir directamente en los negocios troyanos y ofrece al lector el secreto mejor guardado del mito: la lujuria de Helena, con quien Hockenberry mantiene varios encuentros amorosos. "Yo sé mucho de lujuria» llegará a decir Helena al escólico en uno de ellos y, para demostrarlo, le contará su desdichada historia:

-Mi madre fue Leda, a quien llamaban «la hija de la noche» -dijo ella con desenfado-, y Zeus acudió a ella y se la folló mientras tomaba la forma de un cisne... un cisne enorme y caliente $[\ldots]$.

-[...] Cuando yo tenía once años, [...] fui secuestrada en el templo de Artemisa Ortia por Teseo, el que unificó las ciudades del Ática en la ciudad de Atenas. Teseo me dejó embarazada: le di una hija, Ifigenia, a quien no pude tratar con amor y que entregué a Clitemnestra para que la criara con su marido, Agamenón, como si fuera suya ${ }^{26}$. [...]

-[...] El gran rey Menelao me reclamó como esposa, aunque a ese tipo de hombre les encantan las vírgenes porque aman su linaje más que a la vida, aunque yo era un bien manchado en un mundo de hombres que aman tanto a las vírgenes. Y luego Paris, impulsado por Afrodita, vino a secuestrarme de nuevo para traerme a Troya y convertirme en su... trofeo (Ilión I, p. 355-356).

Del mismo modo, la presencia de los moravecs en las llanuras de Ilión encuentra una base en el relato homérico:

-Périmo, noble hijo de Megas -dijo Mahnmut-, estas formas oscuras son ayudantes, forjados por Hefesto, pero traídos aquí por Aquiles para ayudarnos a ganar la guerra contra los dioses. [...]

Según Homero, envió Orphu, los «ayudantes» eran una especie de androides creados en la fragua de Hefesto con partes humanas, y los dioses y algunos mortales los usaban como si fueran robots ${ }^{27}$.

26 Tal como se observa en este punto, en algunos casos Simmons se atreve incluso a apartarse de las versiones canónicas e introduce variantes míticas, en un ejercicio académico inesperado, como si se tratara de un poeta antiguo que elige o varía una versión del mito. Como se sabe, Ifigenia será la víctima sacrificada por Agamenón para llevar las naves hasta Ilión; la mayoría de las fuentes la tiene por hija de Agamenón y Clitemnestra, pero la variante que aparece aquí, según la cual es hija de Helena y Teseo, está documentada en Pausanias 2, 22, 6-7, quien cita a Estesícoro, Euforión y Alejandro Étolo, según A. Ruiz DE ElvirA, Mitología clásica, Madrid, ${ }^{2} 2000$, p. 384. Aunque con reservas, es posible que este trastoque pueda interpretarse como una prolepsis o castigo anticipado a Helena, como culpable de la guerra de Troya. Se trata en todos los casos de procedimientos que engarzan además con la actividad filológica de los moravecs, a la que nos hemos referido antes (cf. p. 206).

27 En la visita de Tetis a la morada de Hefesto, Homero presenta (Il. XVIII, 417-420) una corte de autómatas: «Marchaban ayudando al soberano unas sirvientas / de oro, semejan- 
¿Me estás diciendo que en la Ilíada hay androides y moravecs?, preguntó Mahnmut.

La Ilíada tiene de todo, dijo Orphu (Ilión II, p. 393-394).

Junto a estas líneas rectoras, se reconocen otros elementos que activan formatos de subversión adicional, aunque siempre supeditados a las primeras. Veamos algunos de ellos.

\section{Las modificaciones en la historia transmitida}

Si la fuente literaria de la que se parte son los poemas homéricos y las narraciones mitológicas conocidas y transmitidas en todo Occidente, entonces la mayor transgresión posible consiste en no seguir las pautas marcadas por esas fuentes, alejándose de ellas en una reescritura personal que, en muchos casos, no está condicionada por el género.

Este procedimiento de subversión es evidente, por ejemplo, en el propio desenlace de la primera trama argumental, en la que, tras la intervención manipuladora de Hockenberry, Aquiles redirige el enfrentamiento entre griegos y troyanos hacia los dioses, provocando el derrocamiento final de Zeus. La ideología que se subvierte es la inmortalidad del dios supremo, es decir, la creencia en la necesidad de la divinidad. Cierto es que la amenaza del derrocamiento de Zeus estaba inherente en el relato hesiódico (Teog. 523-531) y fue recogida por Esquilo en Prometeo encadenado, pero la mitología griega salvó la situación con la evolución moral de Zeus en un dios justo. Fue la mejor solución que el pensamiento mítico griego encontró para conciliar tensiones entre ideas antagónicas: el rechazo social a la tiranía en la Tierra, cuyo reflejo en el Olimpo estaba encarnado por Zeus, y la necesidad de un ser superior garante de la justicia entre los hombres, principio capital del pensamiento filosófico griego. Para que Zeus pudiera encarnar también la justicia era necesario introducir una evolución en el carácter divino, y ese cambio se ha transmitido a Occidente a través del mito de Prometeo: el titán rebelde que se enfrenta al tirano y le fuerza a negociar un tratado de conducta justo hacia su criatura más débil, el hombre.

Sin embargo, esta solución ya fue obviada por los poetas románticos ingleses. John Keats canta en Hiperión la negativa de los titanes a ceder el poder a los dioses olímpicos, en una exaltación de valores que representan los antiguos dioses frente a las nuevas deidades: la fuerza, la inmovilidad, la grandeza, lo primitivo y el sentido de justicia que emana de esos valores, es decir, la inmutabilidad de las cosas. Pero fue especial-

tes a vivientes doncellas. / En sus mientes hay juicio, voz y capacidad de movimiento, / y hay habilidades que conocen gracias a los inmortales dioses» (trad. E. Crespo, Madrid, Gredos, 1991). Sobre estos y otros personajes similares en el mito griego, véase G. LIVELEY, "Science fictions and cyber myths», en V. Zajko \& M. Leonard (eds.), Laughing with Medusa: Classical myth and feminist thought, Oxford, Oxford University Press, 2006, p. 275-294 (esp. p. 275-278). 
mente Percy B. Shelley en Prometeo desencadenado ${ }^{28}$ quien optó por la caída de Zeus, la liberación del titán, la fuerza del amor y la llegada de un dios justo, Demogorgón. Esta última tradición es la que adopta Dan Simmons, aunque matizándola, ya que permite que este Zeus posthumano muera a manos de Aquiles y que Hefesto, el más deforme de los dioses (factor importante en su esfera de valores), sea elegido nuevo rey. En cualquier caso, que Zeus muera a manos de Aquiles solo es posible porque este Zeus no es verdaderamente inmortal.

La presencia constante, a veces evidente, latente otras, de los poetas ingleses románticos John Keats, Percy B. Shelley y George G. Byron, además de responder probablemente a gustos personales del autor, adquiere un doble significado literario: ellos fueron los poetas que cantaron de nuevo a la antigua Grecia, recuperaron la oda de Píndaro, dignificaron los poemas homéricos o escribieron dramas imitando a Esquilo, en una palabra, fueron los responsables de introducir el mundo griego en Europa y vivificaron la lírica europea. Pero, además, fueron poetas revolucionarios, al negarse a aceptar la preceptiva aristotélica y al oponerse a los regímenes autoritarios que oprimían a sus países ideales, Italia y Grecia. Fueron revolucionarios de palabra y obra, y, aunque ahora son considerados poetas clásicos y cultos, en su momento subvirtieron un sistema de valores provenientes del Medievo y consolidados en la cultura bienpensante francesa e inglesa ${ }^{29}$. Por tanto, el uso que hace Dan Simmons de sus poemas y su presencia en la novela no puede ser causal, sino que está ligado a una intencionalidad poética, su admiración por Grecia, y social, su rebeldía contra la tiranía. Así, por ejemplo, tras la caída de Troya, la reflexión de Hockenberry sirve para incluir los versos de uno de estos autores:

Mientras contemplaba el escenario cambiado [...], recordé un canto del Don Juan de Byron, escrito cuando el poeta había visitado el lugar [scil. las ruinas de Troya] en $1810 \mathrm{y}$ sentido a la vez la conexión con la heroica historia y la distancia que lo separaba de ella:

Altos montículos sin mármol ni un nombre, una enorme llanura recta, rodeada de montañas

28 Prometheus Unbound (1820). Continuando con el argumento abierto por Esquilo en la tragedia Prometeo encadenado, posiblemente la segunda de la trilogía que el poeta presentó en el festival teatral de las Panatenaicas de Atenas, que incluiría también las obras Prometeo portador del fuego y Prometeo liberado, hoy perdidas (cf. A. LESKY, Historia de la literatura griega, Madrid, ${ }^{3} 1985$, p. 283), Percy B. Shelley decidió desarrollar la propuesta rebelde consagrada en la tragedia citada y liberar al héroe injustamente tratado por el tirano Zeus. Este planteamiento subvertido se explica por el deseo artístico y político de Shelley de romper con la estética de la lírica anterior y luchar contra los regímenes que subyugaban a los jóvenes países europeos (en especial clamaba por la libertad de Grecia contra la opresión turca): «la nostalgia de una patria ideal» (cf. G. HiGHET, La tradición clásica, México, ${ }^{3}$ 1996, II, p. 109).

29 Véase la clarificadora introducción de G. Highet, La tradición... al capítulo «La era de la revolución», p. 103-119. 
y el Ida en la distancia, aún el mismo,

un viejo Escamandro (si es él) queda;

la situación parece aún formada para la fama:

cien mil hombres combatirían de nuevo

con facilidad; pero donde yo buscaba las murallas de Ilión,

la oveja tranquila pace y la tortuga se arrastra

(Olympo II, p. 397).

Un segundo aspecto radicalmente transformado afecta a la célebre expresión «la caída de Troya» (the fall of Troy), que por razones de tradición tiene un sentido unívoco. El dominio del texto clásico y la sabia conducción de las tres líneas argumentales permiten al autor dar un sentido novedoso e impactante, diferente de las distintas evaluaciones morales que se ha dado al acontecimiento a lo largo de la historia, basada en una lectura literal del sintagma. Efectivamente, la caída de Troya a la que se refieren los protagonistas de la historia constituye el desplome real de una ciudad entera que, durante un periodo indeterminado, ha flotado en el limbo del tiempo y del espacio por decisión de los dioses posthumanos. Vencidos estos, Aquiles y los aliados del bando humano logran recolocar físicamente la ciudad donde un día estuvo. Así lo explica el escólico:

Yo había enseñado la Ilíada durante más de veinte años en la Universidad de Indiana y en otras partes, pero nunca había pensado en ir a Troya, a las ruinas de Troya a la costa de Turquía. Pero había visto suficientes fotos del lugar a finales del siglo xx y principios del Xxi. El lugar donde Ilión habia aterrizado de golpe como la casa de Dorothy ${ }^{30}$ se parecía más a las ruinas de Troya en el siglo Xxi (una pequeña zona llamada Hisarlik) que al vivo emporio que había sido Ilión (Olympo II, p. 397).

Por tanto, las connotaciones tradicionalmente ligadas a la expresión «la caída de Troya», a saber, su conquista, saqueo y destrucción total, adquieren en este libro valores contrarios de recuperación y salvación de una ciudad y su pueblo, llamados, además, a enseñar las artes y el modo de vida tradicional a los humanos de la Tierra, olvidados de todo su pasado y patrimonio cultural. Este procedimiento lingüístico de desmonte de metáforas ${ }^{31}$ es un procedimiento usual para crear ironía, recurso típico de la subversión.

30 Esta y otras alusiones a $E l$ mago de $O z$ forman parte de un recurso amplio a la cultura popular en la obra. Véase al respecto, infra, p. 218-220.

31 El desmonte de metáforas se basa en el concepto, fraguado por G. LAKOFF y M. JoHNSON en Metáforas de la vida cotidiana (Madrid, Cátedra, 1991), de «metáfora ontológica» (p. 63 ss.), donde CAER genera equivalencias metafóricas con arruinarse, perderse, destruirse. Por tanto, el sintagma "la caída de Troya» crea fácilmente asociaciones metafóricas con la ruina y la destrucción. El desmonte de metáforas, es decir, la lectura no metafórica de una expresión, es un recurso cómico habitual, usado como fuente de malentendidos. 
La mayor subversión de este cambio es tal vez sentimental, puesto que cualquier lector de la Ilíada y la Odisea sentía un dolor profundo al ver destruida una forma de civilización avanzada, habitada por seres sensibles y dignos de admiración como Príamo, Andrómaca, Héctor o Casandra. Esta ruptura mítica compensa el lamento que todas las literaturas occidentales han proferido ante la «caída de Troya» ${ }^{32}$.

\section{La subversión en los personajes}

En línea con el procedimiento abordado en el epígrafe anterior, la subversión se produce también a través de las distintas categorías de personajes que protagonizan el relato homérico.

En lo que a los dioses respecta, los hipotextos sobre los que se trabaja son básicamente la cosmogonía de Hesíodo y la mitología griega. A pesar de la extemporaneidad del mito, colocar el panteón olímpico en un futuro remoto implica -por oposición al carácter fundacional que se otorga a estos relatos- una subversión de su naturaleza misma.

Por su parte, los hipotextos sobre los que se opera en el plano de los héroes son los textos homéricos sobre la guerra de Troya y las aventuras de Ulises. Podemos mencionar cuatro casos significativos de variación importante con respecto a la tradición: Ulises, Aquiles, Héctor y las mujeres troyanas.

Odiseo no regresa a Ítaca y se queda con Circe. Por obra y gracia de la tecnología y la teoría de los mundos paralelos, Odiseo tiene la capacidad de ser protagonista al tiempo en dos escenarios: en la Tierra junto a los antiguos humanos, completamente desamparados e ignorantes, donde su avatar Nadie se arroga el papel de guía y jefe para enfrentarse a los voynix, y en Marte, como participante de la guerra, desde donde viaja en la nave moravec y se ofrecerá como moneda de cambio para permitir a estos organismos acceder a la Tierra y salvarla. Para ello deberá entregarse a los deseos de una diosa insaciable, Circe, que le impide el regreso a su hogar. El héroe es retratado con todos los aspectos positivos, que no siempre posee en el mito, pues no es mujeriego, no es engañador ni mentiroso, no es locuaz, sino más bien taciturno, y se enfrenta de cara a sus enemigos, sin ocultarse en estrategias. Todo ello supone la rehabilitación de

32 Los primeros grandes relatos de la caída de Troya proceden de los poetas romanos Virgilio (Aen. II, 13-267) y Ovidio (Met. XII, 399-575), pero ya antes hubo un poema épico con el título El saco de Troya o Iliupersis, de Arctino de Mileto, de cuyo argumento queda el resumen de Proclo. Pero la intención de cambiar la óptica de Homero y justificar a los troyanos surgió a partir de las obras de Dares Frigio (De excidio Troaie historia) y Dictis Cretense (Ephemeridos belli Troaini libri), usadas por Benoît de Sainte-Maure en su poema Le roman de Troie. 
un héroe con luces y sombras para el pensamiento occidental ${ }^{33}$. Ulises siempre fue en el pensamiento antiguo un héroe ambiguo, metáfora de un período de transición, del héroe épico al héroe moderno. La flexibilidad de su carácter y su capacidad para solventar situaciones vitales de modo oblicuo, además de su dimensión viajera y curiosa, lo han convertido en el héroe occidental por excelencia ${ }^{34}$.

Aquiles derroca a Zeus. Este personaje es en la tradición un héroe poco sociable $y$, en general, bastante cruel. Estos rasgos se conservan con fidelidad en la saga, pero se añaden tres acontecimientos que cambian su destino: en primer lugar, cree que la muerte de Patroclo es obra de Atenea ${ }^{35}$, de modo que decide unirse a los troyanos en contra de los dioses, considerados los verdaderos enemigos de los hombres, cambio radical de perspectiva en la guerra de Troya. En segundo lugar, se enfrenta a la amazona Pentesilea, a la que mata y de la que se enamora, como narra algún mito ${ }^{36}$; llevado de ese impulso amoroso, decide resucitarla para vivir con ella sin celebridad ni fama, como otros tantos cientos de hombres y mujeres. De este modo, se subvierte de raíz la ideología épica de la Ilíada, según la cual la fama del hombre se obtiene en el campo de batalla. Por último, en un intento desesperado de resucitar a su amor, baja a los infiernos, al Tártaro para ser exactos, acompañado de Hefesto, para tratar de convencer a los dioses primigenios de que el mundo divino necesita un cambio: la muerte del dios supremo. En esas condiciones, Aquiles puede regresar a la Tierra y enfrentarse a Zeus para aniquilarlo.

Héctor no muere, sino que se alía con Aquiles para luchar contra los dioses. Posiblemente sea esta la mejor noticia para todos los románticos del mundo que alguna vez acometieron la lectura de la Ilíada. La muerte de Héctor constituye uno de los momentos más desgarradores del poema, puesto que este héroe encarna los valores más queridos de la sociedad occidental: hermano leal, hijo obediente, esposo amante, padre cariñoso, jefe aguerrido y defensor valeroso de su ciudad. Héctor acapara toda la gloria del poema, puesto que muere defendiendo valientemente frente a Aquiles las murallas

33 Sobre la fortuna posterior de la figura de Odiseo, véase la rica obra de P. BoITANI, $L a$ sombra de Ulises. Imágenes de un mito en la literatura occidental, Barcelona, Península, 2001.

34 Según algunos autores, la rehabilitación de Odiseo se configura sobre todo en la Odisea, puesto que es en este poema donde el héroe muestra su faceta más humana, pero también más viajera. El sufrimiento, la constancia y la vulnerabilidad son los aspectos que mejor lo encarnan; cf. P. CitaTi, Ulises y la Odisea. El pensamiento iridiscente, Barcelona, Galaxia Gutemberg, 2008 (Mondadori, 2002).

35 En realidad, en la Patroclea (Il. XVI, 786-804), Homero refiere que es Apolo el que golpea, desarma y desata la coraza de Patroclo, dejando a Héctor el camino expedito para darle muerte.

36 Diodoro Sículo 2, 46, 5; Apolodoro, Epitome 5, 1; Quinto de Esmirna 1, 18ss: para más detalle, véase Ch. Harrauer \& H. Hunger, Diccionario de mitología griega y romana, Barcelona, Herder, 2008, p. 668. 
de Troya ${ }^{37}$. Sin embargo todo su brillo se esfuma en cuanto sobrevive al combate y se convierte en aliado de Aquiles para hacer frente a estos dioses crueles, que asolan la ciudad. Es innegable que una muerte a tiempo tiene mucho más glamour que las riñas diarias con su esposa, la desconfianza hacia Aquiles, los enfados con Paris y otros actos del mundano vivir.

El papel de las mujeres. Las mujeres troyanas, por último, asumen una función activa en el relato y complotan para evitar la ruina de Troya, idea que procede de Las troyanas de Eurípides. Lideradas por Helena, Hécuba, Andrómaca, Casandra, Teano y Laódice, como garantes de la organización social, comprenden que griegos y troyanos deben convertirse en aliados, para lo cual traman el complot que va a ser definitivo para lograr la paz. El dinamismo de este grupo supone una mirada moderna y realista ${ }^{38}$ sobre el papel de las mujeres en una ciudad amenazada, porque todas ellas son madres, esposas o hermanas de hombres en peligro. No solo se lamentan, como en la Ilíada, sino que toman la iniciativa, lo que implica mentir, engañar o matar si es necesario. Además, el novelista da muestras de un conocimiento profundo del comportamiento femenino grupal, cuando imagina que entre las troyanas y Helena existe una profunda amistad o, al menos, un compromiso inquebrantable de salvar Troya. De todos los personajes míticos femeninos, el de la hermosa Helena es el que tiene más calado, como corresponde a un carácter traicionero y apasionado, tal y como se la describe aquí.

\section{El ropaje del lenguaje tecnológico}

En la ciencia ficción el desarrollo de la técnica constituye la mejor actualización del ropaje del lenguaje mágico antiguo, puesto que, al fin y al cabo, todos los instrumentos de los que se dotan los dioses posthumanos desempeñan el papel de herramientas mágicas, tan útiles en la mitología griega, como, por ejemplo, las que sirven a Perseo para matar a Medusa: el casco de Hades que lo hace invisible, las sandalias de Hermes que le permiten volar, el escudo bruñido para no mirar al monstruo directamente y poder cortarle la cabeza, y el zurrón donde guardarla. Precisamente el primero de ellos es recuperado en clave tecnológica:

-Es un teleportador cuántico personal como el que utilizan los dioses ${ }^{39}$-dice en voz baja-. Puede teleportarte a cualquier lugar que visualices. Este disco TC en concreto

37 Su humanidad queda aún más acentuada en el contraste con un despiadado Aquiles, que le niega su último deseo: que su cadáver no sea ultrajado por los perros; véase Hom., $\mathrm{Il}$. XXII, 337-366.

38 Más propia, en todo caso, de la comedia antigua (piénsese, por ejemplo en Lisístrata de Aristófanes) que de los varoniles valores de la épica. Con todo, no hay que olvidar que el planteamiento aristofánico también fue una propuesta utópica para resolver un conflicto bélico.

39 La propia Atenea se sirve de él para evitar ser vista por Ares; cf. Hom., Il. V, 845. 
te permite seguir el rumbo cuántico de los dioses cuando cambian de fase a través del espacio de Plank, pero nadie (excepto la deidad que me lo entregó) puede ver tu rumbo. ¿Comprendes? [...]

-Este es el Casco de la Muerte - dice ella, colocando el casco de cuero repujado sobre mi cabeza como si fuera una capucha-. El Casco de Hades. Lo fabricó el propio Hades y es la única cosa en el universo que puede ocultarte de la visión de los dioses (Ilión I, p. 72-73).

La tecnología permite así resemantizar la mitología, aportando nuevos sentidos. Los artefactos nanotecnológicos, la manipulación genética o el control sobre la física cuántica proporcionan una explicación en clave contemporánea a la magia que destilan los versos homéricos. En este sentido, la ciencia ficción utiliza los avances tecnológicos como una suerte de útil explicativo que, en cierto modo, permite una lectura racional o evemerística del relato mitológico tradicional y que resulta más llamativa aún, en su condición hipermoderna, al contrastarse con formas sociales premodernas ${ }^{40}$. Así se explica la intervención directa de un dios en el conflicto ${ }^{41}$ :

Febo Apolo, señor del arco plateado, se TCea ${ }^{42}$ y solidifica entre el enloquecido Diomedes y el teucro caído, y mantiene al aqueo a raya con un pulsante hemisferio de campo de plasma. Cegado por la sed de sangre, Diomedes acomete contra el campo de fuerza, su propio campo de energía choca rojo contra el escudo defensivo amarillo de Apolo (Ilión I, p. 164).

\section{La inmoralidad de los dioses frente a la moralidad de las máquinas}

La exageración de defectos propios de la vida privada -la envidia, los celos, el deseo de poder o la lujuria-, que afectan por igual a dioses y hombres, aunque ya estaba presente en Homero y en el mito, no aparecía de forma tan desvergonzada, hiriente y descarada como aquí. Esta intención ofensiva de los dioses, dirigida a los mortales, provoca una conducta tan poco ejemplar que los convierte en los antihéroes del relato, de modo que, mientras en el mito la necesidad de la divinidad ni se discute, en la novela se introduce

40 Cf. Ch. Palmer, «Galactic empires...», p. 73.

41 La aparición de Apolo sucede justo después de que Afrodita, que intentaba proteger a su hijo Eneas, sea herida por un furibundo Diomedes, episodio que reelabora Simmons. La diferencias que impone el lenguaje con respecto a su modelo son patentes en la descripción homérica de la misma entrada en escena divina: «Lo protegió [scil. a Eneas] entre sus brazos Febo Apolo / con una sombría nube, por si algún dánao de veloces potros, / le disparaba el bronce en el pecho y le quitaba el aliento vital» (Hom., Il. V, 344-346).

42 Verbo que indica el desplazamiento en el tiempo y el espacio, por medio de un TC, aparato inventado ad hoc. 
la exigencia de acabar con ella, no solo por su comportamiento, sino por el hecho, malvado en sí mismo, de la recreación de la guerra de Troya como simple divertimento. En el fondo prevalece la idea de que se trata de falsos dioses y de que su existencia no se justifica ni por el destino ni por la necesidad.

Frente a este comportamiento, su reverso no está representado por los hombres, perdidos en esa Arcadia feliz y falaz en que se ha convertido la Tierra, sino por la actitud nostálgica de los moravecs, mecanismos biomecánicos que sienten admiración, casi veneración, por la civilización humana que fue capaz de producir obras señeras del pensamiento, creaciones que ellos leen e interpretan como nuevos filólogos. Pero, además, tienen en su genética o en su configuración técnica, la función de velar por la vida de los hombres, de sacrificarse por ellos, de salvarlos de sus enemigos (principios básicos de la robótica). Y gracias a ese comportamiento moral llegan a enfrentarse a los dioses posthumanos de Marte y a los enemigos que intentan asolar la Tierra y acabar con los pocos humanos que resisten. La subversión, ideológica, se basa en esa falsa condición divina y en la aplicación soberbia, esto es, de hybris, de la tecnología cuántica. Frente a ellos, los moravecs, las quasi máquinas, son generosos y tienen sentimientos altruistas.

\section{Las referencias a la cultura popular}

Las referencias culturalistas, a las que ya nos hemos referido, se combinan sin fricción con la inclusión de elementos propios de los relatos de ficción galáctica canónicos (los faxnódulos que permiten el teletransporte, por ejemplo, típicos de la space opera) y las continuas alusiones a la cultura popular estadounidense en sentido amplio, algo justificable por ubicarse la ciencia ficción en los márgenes del canon literario. Son muchas las alusiones a la contemporaneidad de los lectores, o al menos a un momento reconocible como pueden ser las alusiones a la política estadounidense ${ }^{43} \mathrm{o}$ a los atentados del 11-S, la referencia, con su mismo nombre y espíritu, al Burning Man, festival, entre lúdico y esotérico, que se celebra anualmente en el desierto de Nevada, o a la mítica serie televisiva Star Trek. Incluso el escenario elegido para el apoteósico encuentro sexual final entre Odiseo y Circe es un auto-cine, paisaje pop por excelencia para los escarceos amorosos de los adolescentes estadounidenses de los años 50 y 60. De manera semejante, la ciudad de Cráter París (resto de la capital francesa devastada por efecto de

43 En estos casos, el anclaje referencial con la contemporaneidad de los lectores provoca una interpretación arqueológica de ese momento histórico, que resulta ubicado en un futuro remoto a través de la figura del escólico Hockenberry. Así se aprecia en ejemplos como el siguiente: «No demuestro ninguna falta de respeto hacia nuestro padre -dice Ares por fin, y su voz me recuerda a la de Richard Nixon cuando hablaba al micrófono oculto del Despacho Oval que sabía que estaba allí. Poniendo sus mentiras on the records (Ilión I, p. 160). 
un meteorito) ha visto sustituido el icono de la Torre Eiffel ${ }^{44}$ por una enorme representación femenina, "la putain énorme», un híbrido grotesco entre el Moulin Rouge y la Estatua de la Libertad, que podría haber sido concebido por los diseñadores de Las Vegas y cuyo significado se ignora:

De trescientos metros de altura, la burda reproducción de una mujer desnuda parecía hecha de algún polímero claro. [...] Los pechos eran enormes, globulares, caricaturescos; se llenaban y se vaciaban alternativamente con líquido rojo fotoluminiscente que hervía y cuyos niveles ahora subían y ahora bajaban en cascada por el interior del vientre y las piernas, y luego subían de nuevo por los brazos levantados y el rostro sonriente (Ilión I, p. 133).

Este tipo de guiños al lector contrastan con las situaciones representadas en dos de los planos (el Marte futuro, las criaturas artificiales) y con la incapacidad de memoria histórica, por su condición de iletrados, de los antiguos humanos. Así, la topografía da pie a continuas deformaciones: Garded Lyon-irreconocible en su traducción española, «León protegido»-, en lugar de Gare de Lyon, los Campos Ulises, con referente claro, e incluso el Lover por el Louvre, transformado a veces en Luv, deformación que en inglés puede ser cariñosa, pero que es también utilizada como recurrente sobrenombre por algunas estrellas del porno estadounidense. Todo ello refuerza el tópico de París, no ya como capital del amor, sino más bien del sexo. Y en este sentido, cabe también mencionar, por último, la crudeza y morosidad con que se describen los encuentros sexuales de los personajes, con presencia de muchos de los tópicos del género pornográfico, sobre todo en los titánicos escarceos de los dioses:

Por muchas veces que Hera hubiera visto el divino falo de su esposo erecto, nunca dejaba de dejarla sin respiración. Todos los dioses varones eran... bueno, dioses... pero en su casi olvidada Transformación en olímpicos, Zeus había guardado los atributos más impresionantes para sí. Esa vara púrpura que se apretaba ahora entre sus pálidas rodillas era el único cetro que aquel rey de dioses necesitaría para crear asombro entre los mortales y envidia entre los otros dioses (Olympo I, p. 102).

Son precisamente estas alusiones al imaginario colectivo las que incorporan la obra en la sociedad de consumo y en la contemporaneidad, permitiendo así la subversión exitosa del relato homérico y subrayando su incuestionable vigencia.

44 Cuyo recuerdo permanece, con todo, en el eiffelbahn, nombre que se da a un medio de transporte, suerte de teleférico, que aparece como guiño a esta suplantación. 


\section{Conclusiones}

De este análisis es posible extraer las siguientes ideas principales, esas que definen de manera original la subversión en esta obra:

-La primera subversión no es otra que la mezcla de géneros antagónicos: un género asociado a la cultura popular, la ciencia ficción, y otro marcadamente culto (aunque no lo fuera en su origen), la épica homérica, estrechamente asociada a la relectura que de ella hizo la lírica inglesa del Romanticismo.

-La subversión que maneja el autor atiende a varios niveles: el más obvio es la subversión mítica de la guerra de Troya, pero este uso aparentemente esperable se hace más llamativo gracias al recurso de ofrecer al lector el rigor de los textos originarios. Admirable y arriesgado juego intertextual, cuya explotación intelectual depende del tipo de lectura que realice cada lector.

-La inserción de elementos contemporáneos al lector es otro guiño subversivo, puesto que las referencias a un mundo conocido se unen a elementos extremadamente cultos, pero todos ellos son reliquias arqueológicas o meros productos de consumo turístico para las criaturas del futuro.

-De las tres historias que se cuentan, la que mejor funciona es, a todas luces, la narración homérica. Sin restar un ápice de mérito a Simmons, el éxito ya estaba asegurado, de lo cual se extrae el siguiente corolario: que la historia homérica es de alcance universal, lo que permite defender que la tradición clásica continúa muy viva en el siglo XXI.

Rosario López Gregoris, Luis UnCETA GÓMEZ

Departamento de Filología Clásica

Universidad Autónoma de Madrid

28049, Madrid

rosario.lopez@uam.es; luis.unceta@uam.es 